\title{
Conf. $940813--39$
}

MECHANISMS OF IRON-BASED CATALYSIS INVESTIGATED USING MODEL COMPOUNDS
J. C. Linehan
J. A. Franz
D. W. Matson
D. M. Camaioni
J. G. Darab
S. T. Autrey

August 1994

Presented at the

American Chemical Society National Meeting

August 21-26, 1994

Washington, D.C.

Prepared for

the U.S. Department of Energy

under Contract DE-AC06-76RLO 1830

Pacific Northwest Laboratory

Richland, Washington 99352 


\section{DISCLAIMER}

This report was prepared as an account of work sponsored by an agency of the United States Government. Neither the United States Government nor any agency thereof, nor any of their employees, make any warranty, express or implied, or assumes any legal liability or responsibility for the accuracy, completeness, or usefulness of any information, apparatus, product, or process disclosed, or represents that its use would not infringe privately owned rights. Reference herein to any specific commercial product, process, or service by trade name, trademark, manufacturer, or otherwise does not necessarily constitute or imply its endorsement, recommendation, or favoring by the United States Government or any agency thereof. The views and opinions of authors expressed herein do not necessarily state or reflect those of the United States Government or any agency thereof. 


\section{DISCLAIMER}

Portions of this document may be illegible in electronic image products. Images are produced from the best available original document. 


\title{
MECHANISMS OF IRON-BASED CATALYSIS INVESTIGATED USING MODEL COMPOUNDS
}

\author{
John C. Linehan, Dean W. Matson, John G. Darab, S. Thomas Autrey, \\ James A.. Franz, and Don M. Camaioni. \\ Pacific Northwest Laboratory1 \\ P.O. Box 999, Richland, WA, 99352
}

Key words: Model compounds, catalysis, iron oxides.

\begin{abstract}
The catalytic mechanism of highly active, nanophase, iron-based coal liquefaction catalysts was investigated using a series of model compounds. The iron-oxide phases ferric oxyhydroxysulfate (OHS), 6-line ferrihydrite, hematite, and goethite, were evaluated as catalyst precursors with systematically substituted diphenylmethanes in the presence of a hydrogen donating solvent. The activity of the catalysts was observed to be dependent upon the functionality on the model compounds. The results of these model compound studies and their relationship to possible reaction mechanisms are presented.
\end{abstract}

Introduction. There has been recent interest in the development of inexpensive, new, and potentially disposable, catalysts for the first stage direct liquefaction of coal.2 A major emphasis has been placed on developing highly active iron-based liquefaction catalysts as substitutes for the current molybdenum-based catalysts which are more expensive. The new iron-containing catalysts for this purpose have been screened using either model compounds or select coals. While numerous studies have been undertaken to synthesize and test iron-based catalysts with enhanced catalytic activity for hydrogenolysis, 2 few studies have systematically focused on the bond cleavage or hydrogenation mechanism(s) involved when these catalysts are employed. ${ }^{3}$

In previous papers we have focused on either developing techniques for the production of nanoscale iron-oxides or the identification of active iron oxide catalyst precursor phases. ${ }^{4-6}$ In this paper we concentrate on the organic structures which are attacked by the iron-based catalysts. We describe our preliminary results using systematically altered model compounds with a variety of iron oxide catalyst precursors to elucidate carbon-carbon bond scission pathways supported by iron-based catalysts.

Experimental. The model compounds diphenylmethane (DPM) (Aldrich) and 4,4'-dimethyl diphenylmethane (4,4DPM) (TCI) were used as received. The model compounds methyl diphenylmethane (MeDPM), 2,5 -dimethyl diphenylmethane (Me2DPM), and 2,4,6-trimethyl diphenylmethane (Me3DPM) were synthesized from neat mixtures of the appropriate methylated aromatic (toluene, p-xylene, and mesitylene respectively) and benzyl alcohol with the addition of concentrated sulfuric acid. The reaction products were distilled under reduced pressure and the products were shown to be $99 \%$ pure by GC and proton NMR. The only exception was MeDPM which was found to be an inseparable 50:50 isomeric mixture of 2-methyldiphenylmethane and 4methyl diphenylmethane by NMR.

The catalyst precursors were made according to literature procedures and milled to -325 mesh, except for the 6-line ferrihydrite ${ }^{4}$ which was produced by the RTDS method ${ }^{5,7}$ at low reaction temperatures and was also sieved to -325 mesh. The catalyst testing procedure, which has been detailed previously, consisted of loading $15 \mu \mathrm{l}$ of the model compound with $3 \mathrm{mg}$ of the catalyst precursor, $3 \mathrm{mg}$ of elemental sulfur and $100 \mathrm{mg}$ of pure (>99\%) 9,10-dihydro-phenanthrene into a. Pyrex tube. The tube was sealed under vacuum and heated at $400 \pm 3^{\circ} \mathrm{C}$ for 1 hour in a fluidized sand bath. The products were identified by GC and the residual model compounds were quantified with an internal standard.

Results and Discussion. Table I shows the percent consumption of the five model compounds using four iron oxide catalyst precursors. As can be seen from the Table, the relative order of model compound consumption increases with increasing methyl substitution. Figure 1 shows these results as a function of the number of methyl groups on substituted diphenylmethanes. Both Table I and Figure 1 show the dramatic increase in consumption of the model compound in going from Me2DPM to Me3DPM. The yields more than double for most of the catalysts. All of the iron oxide precursors used promoted over 75\% consumption of Me3DPM. These results support the findings that many different forms of iron-containing powders have been found to be : bond scission catalysts under the appropriate reaction conditions.

The increase in the percent consumption of model compound correlates with the decrease in $\mathrm{hi}$ oxidation potential of benzene upon increasing methyl substitution. The oxidation potential drops approximately $0.6 \mathrm{~V}$ in going from toluene to 1,2,3,5-trimethylbenzene.8,9 We estimate that the oxidation potentials of the model compounds used here would decrease in a corresponding manner with increasing methyl substitution. The observed relationship between oxidation potential and bond scission enhancement does not necessarily prove a REDOX mechanism. The cyclohexyldienyl radical intermediate generated by a free radical pathway would also be stabilized with an increase in methyl substitution and would increase the rate of bond cleavage. 
The products of the model compound consumption reactions were mixtures of products resulting from cleavage of bonds A, B, and C (see Figure 2). For DPM and 4,4DPM, the products of bond $A$ and bond $B$ cleavage were indistinguishable, the products from bond $A$ being toluene and the methylated aromatic. For MeDPM, Me2DPM, and Me3DPM, the bond A methylated aromatic products were toluene, $\mathrm{p}$-xylene, and mesitylene respectively. Bond $\mathrm{B}$ cleavage yielded benzene and the methylated aromatic with one additional methyl group. For MeDPM, Me2DPM, and Me3DPM, bond B cleavage yielded xylene, 1,2,5-trimethyl benzene, and 1,2,3,5-tetramethyl benzene respectively. Bond C cleavage involved the loss of a methyl group from the model compound and yielded the parent compound minus one methyl group.

For the uncatalyzed reactions, products from bonds $\mathrm{B}$ and $\mathrm{C}$ cleavage predominated. The bond $\mathrm{B}: \mathrm{C}$ cleavage product ratios were less than one and the bond B:A cleavage ratios were greater than one. The small thermal conversions with some of the uncatalyzed model compound reactions precluded accurate or statistically significant reporting of product distributions.

The products of the catalyzed reactions of the methylated diphenylmethane compounds were almost exclusively derived from bond A cleavage. The major products were toluene and the methylated aromatic (toluene, p-xylene, mesitylene) derived from the substituted ring. Very little benzene, from bond $\mathrm{B}$ cleavage, was detected. There was little evidence for methyl cleavage from the methylated diphenylmethanes in the iron catalyzed reactions. This has also been seen for other methylated systems when using other iron and molybdenum-based catalysts. 10 The B:A bond cleavage ratio for the ferric oxyhydroxysulfate catalyzed reaction was over 50 and the $B: C$ ratio over 100 for Me3DPM model compound. The ratios of $\mathrm{B}: \mathrm{A}$ products and $\mathrm{B}: \mathrm{C}$ products increased with increasing number of methyl substitution for a given catalyst. There was little difference in these ratios between the products of reactions involving different catalyst precursors when similar conversions were obtained.

The total amount of the model compound hydrogenation was less than $2 \%$ of the total products for any of the model compounds or catalyst precursors. This is consistent with other results with ironbased catalysts in the presence of sulfur for both diphenylmethane and naphthyl bibenzylmethane, even under high hydrogen pressures.3,4 Other iron-based catalysts have previously been shown to be active for hydrogenation of polycyclic aromatics in the absence of good leaving groups. 10

Summary Iron-based materials catalyze the consumption of more substituted diphenylmethanes faster than less substituted diphenylmethanes. The catalyzed reactions were very selective for cleavage between the aromatic carbon of the most substituted ring and the methylene carbon. Little evidence for catalyzed cleavage of methyl groups was detected. The relative reactivity of the iron oxide precursors was similar to that previously found for NBBM.

Acknowledgements We gratefully thank Dr. Glen Fryxell (PNL) for developing the methodology for the model compound synthesis. The model compound work was supported by the Director, Office of Energy Research, Office of Basic Energy Sciences, Chemical Sciences Division of the Department of Energy and the catalyst development work was supported by the U. S. Department of Energy, Office of Fossil Energy under contract DE-AC06-76RLO 1830.

\section{REFERENCES}

1. Pacific Northwest Laboratory is operated for the U.S. Department of Energy by Battelle Memorial Institute under contract DE-ACO6-76RLO 1830.

2. See the first 21 papers in Energy \& Fuels, 1994, 1, and references therein.

3. Wei, X. Y.; and Zong, Z-M. Energy \& Fuels, 1992, 6, 236. Wei, X. Y.; Ogata, E.; Zong, Z.-M.; and Niki, E. Energy \& Fuels, 1992, 6, 868 .

4. Linehan, J. C.; Matson, D. W.; and Darab, J. G. Energy \& Fuels 1994, 8, 56.

5. Matson, D. W.; Linehan, J. C.; Darab, J. G.; and Buehler, M. F. Energy \& Fuels $1994,8,10$.

6. Darab, J. G.; Linehan, J. C.; Matson, D. W.; and Campbell, J. A. In Proceedings of the 7 th International Conference on Coal Science Vol I, pg 24, 1993.

7. Matson, D. W.; Linehan, J. C.; and Bean, R. M. Materials Lett. , 1992, 14, 222.

8. Gould, I.R; Ege, D.; Moser, J.E.; and Farid, S. J. Am. Chem. Soc. 1990, 112, 4290.

9. Howell, J.O.; Goncalves, J.M.; Amatore, C.; Klasine, L.; Wightman, R.M.; and Kochi, J.K. J. Am. Chem. Soc., 1984, 106, 3968.

10. Tang, Y. and Curtis, C.W. Energy \& Fuels, 1994, 8, 63. 
Table I

Percent Consumption of Model Compounds with

Iron-Based Catalysts at $400^{\circ} \mathrm{C}$ in the Presence of 9,10-Dihydrophenanthrene

\begin{tabular}{|c|c|c|c|c|c|}
\hline $\begin{array}{l}\text { Model } \\
\text { Compound }\end{array}$ & Hematite & Goethite & $\begin{array}{l}\text { dyst Precurso } \\
\text { 6-Line } 1 \\
\text { Ferrihydrite }\end{array}$ & $\begin{array}{l}\text { Fr } \\
\text { Ferric Oxyhydroxy- } \\
\text { Sulfate }\end{array}$ & None \\
\hline DPMa & $\mathrm{nm}$ & $4 \pm 3$ & $6 \pm 3$ & $9 \pm 3$ & 0 \\
\hline MeDPM & $13 \pm 2$ & $3 \pm 2$ & $8 \pm 3$ & $29 \pm 2$ & $1 \pm 1$ \\
\hline Me2DPM & $36 \pm 3$ & $9 \pm 3$ & $19 \pm 2$ & $58 \pm 2$ & $6 \pm 3$ \\
\hline Me3DPM & $86 \pm 5$ & $95 \pm 5$ & $75 \pm 5$ & $98 \pm 2$ & $5 \pm 3$ \\
\hline $4,4^{\prime} \mathrm{DPM}$ & $43 \pm 4$ & $7 \pm 3$ & $6 \pm 2$ & $60 \pm 5$ & $3 \pm 2$ \\
\hline
\end{tabular}

a) See reference 6 .

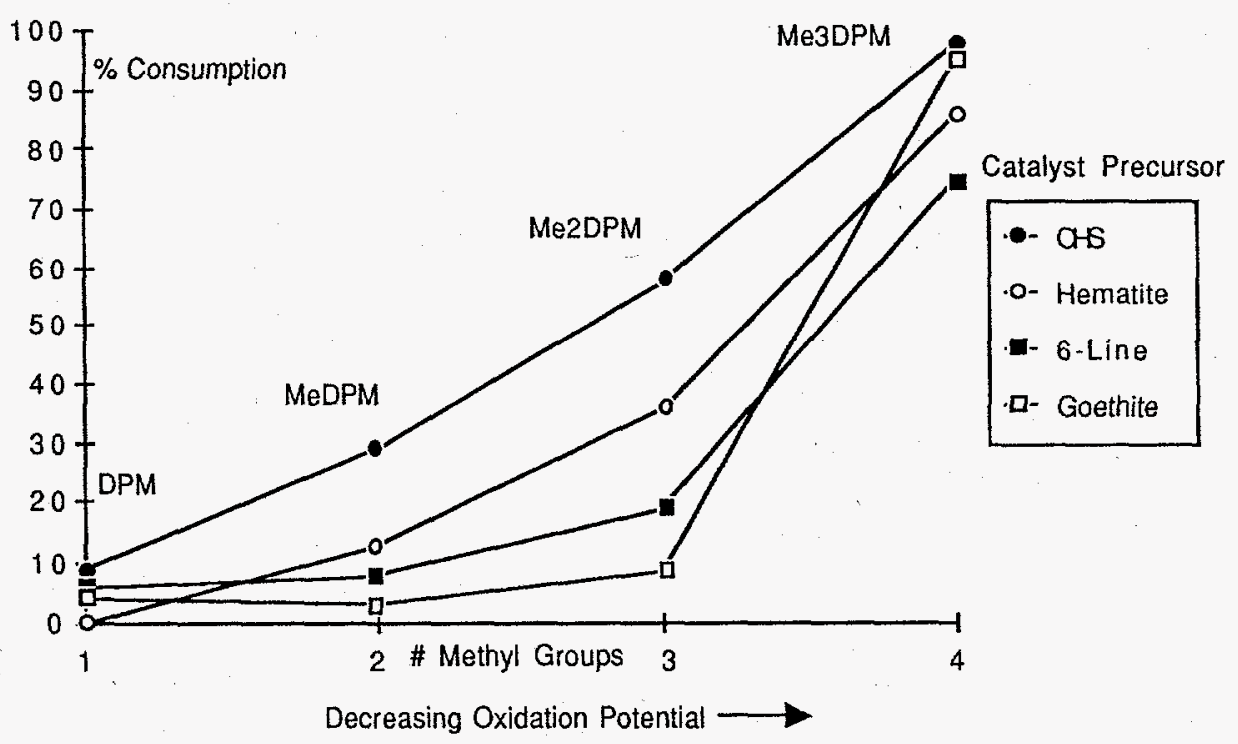

Figure 1. A plot of model compound consumed (at $400^{\circ} \mathrm{C}, 60$ minutes, with catalyst and dihydrophenanthrene) vs methyl substitution for diphenylmethane.<smiles>CC(C)(C)c1ccc(Cc2ccccc2)cc1</smiles>

Figure 2. Schematic of the substituted diphenylmethanes and the bond designation. 